\title{
The contribution of various types of activities to recovery
}

Citation for published version (APA):

Rook, J., \& Zijlstra, F. R. H. (2006). The contribution of various types of activities to recovery. European Journal of Work and Organizational Psychology, 15, 218-240.

https://doi.org/10.1080/13594320500513962

Document status and date:

Published: 01/01/2006

DOI:

10.1080/13594320500513962

Document Version:

Publisher's PDF, also known as Version of record

Document license:

Taverne

Please check the document version of this publication:

- A submitted manuscript is the version of the article upon submission and before peer-review. There can be important differences between the submitted version and the official published version of record.

People interested in the research are advised to contact the author for the final version of the publication, or visit the DOI to the publisher's website.

- The final author version and the galley proof are versions of the publication after peer review.

- The final published version features the final layout of the paper including the volume, issue and page numbers.

Link to publication

\footnotetext{
General rights Owners
rights.

- You may freely distribute the URL identifying the publication in the public portal. please follow below link for the End User Agreement:

www.umlib.nl/taverne-license

Take down policy

If you believe that this document breaches copyright please contact us at:

repository@maastrichtuniversity.nl

providing details and we will investigate your claim.
}

Copyright and moral rights for the publications made accessible in the public portal are retained by the authors and/or other copyright owners and it is a condition of accessing publications that users recognise and abide by the legal requirements associated with these

- Users may download and print one copy of any publication from the public portal for the purpose of private study or research.

- You may not further distribute the material or use it for any profit-making activity or commercial gain

If the publication is distributed under the terms of Article $25 \mathrm{fa}$ of the Dutch Copyright Act, indicated by the "Taverne" license above, 


\title{
The contribution of various types of activities to recovery
}

\author{
John W. Rook \& Professor Fred R. H. Zijlstra Faculty of Psychology
}

To cite this article: John W. Rook \& Professor Fred R. H. Zijlstra Faculty of Psychology (2006) The contribution of various types of activities to recovery, European Journal of Work and Organizational Psychology, 15:2, 218-240, DOI: 10.1080/13594320500513962

To link to this article: https://doi.org/10.1080/13594320500513962

曲 Published online: 24 Feb 2007.

Submit your article to this journal $\pi$

Џll Article views: 2689

Q View related articles $\asymp$

4 Citing articles: 37 View citing articles 


\title{
The contribution of various types of activities to recovery
}

\author{
John W. Rook and Fred R. H. Zijlstra \\ Department of Psychology, University of Surrey, and Surrey Sleep Research \\ Centre, Guildford, UK
}

\begin{abstract}
Stress and fatigue caused by work require daily recovery periods to offset future deleterious consequences to mental and physical health. The aim, therefore, of the current study was to gain insight into recovery processes during a normal week. The main hypotheses were that more time spent on work and work-related activities will have a negative impact on recovery, while more time spent on specific leisure activities would have a beneficial impact on recovery. Using diaries, 46 respondents (average age of 35) provided daily measures of fatigue, sleep, and time spent on recovery activities over 7 days. Recovery activities included time spent on activities that were social, physical, and work-related. Results indicated that whilst low effort and social activities are nonbeneficial to recovery, physical activities significantly predict recovery (i.e., the former increase fatigue whilst the latter decrease fatigue). Sleep quality also emerges as a significant predictor of recovery. The weekend respite appears important to recovery; however, the effect seems already to wane on Sunday evening in anticipation of the Monday workload. The article provides insights into leisure activities and the experience of fatigue.
\end{abstract}

Work-related stress (i.e., that attributed to the work environment) is now a leading cause of sickness absence and lost productivity within UK organizations (DWP, 2002; Moncrieff \& Pomerleau, 2000). Sickness absence (some of which is due to stress) costs British Industry $£ 23$ billion each year (CBI, 2001) and it is estimated that 4\% of the European Union's Gross National

Correspondence should be addressed to Professor Fred R. H. Zijlstra, Faculty of Psychology, Maastricht University, P.O. Box 616, NL 6200 MD Maastricht, The Netherlands. E-mail: fred.zijlstra@psychology.unimaas.nl

The authors would like to thank Dr A. Martin and the Occupational Health Team for helping to secure access to respondents. Gratitude is also extended to all those anonymous respondents who diligently kept diaries for a week, despite no obvious reward for their efforts. Furthermore we would like to thank the anonymous referees for their valuable comments and suggestions.

(C) 2006 Psychology Press Ltd 
Product is spent on work-related mental health (O'Driscoll \& Cooper, 2002). The prevalence of organizational stress and absenteeism, together with increasing work demands (Landsbergis, 2003), means that knowledge regarding the factors associated with insufficient recovery outside of work is important. This article attempts to address the topic of recovery activities after work during a normal working week in as far as they help to reduce the experience of fatigue and impact upon variables such as sleep, thus perhaps indicating the sorts of recovery patterns that are useful to maintain well-being.

The very nature of work requires investing resources and regulating the amount of effort expended in order to complete tasks effectively; inevitably this leads to fatigue as a result of these regulatory processes, both psychological and physiological. Current indications are that fatigue is a common complaint in the working population, with estimated prevalence rates between $22 \%$ and $38 \%$ in the Netherlands and UK respectively (Bültmann, Kant, Kasl, Beurskens, \& van den Brandt, 2002a; Pawlikowska et al., 1994). Occupationally induced fatigue is the short-term effect of a working day and is primarily experienced after a day of work (Sluiter, 1999; Sluiter, Frings-Dresen, van der Beek, \& Meijman, 2001). Self-reports of fatigue in bus drivers were related to increasing job demand, sleep complaints, and other psychosomatic maladies (Kompier, 1988). Rydstedt, Johansson, and Evans (1998) linked aspects of work stress to mental exhaustion after work and research by Sluiter, van der Beek, and Frings-Dresen (1999) showed that aspects of demand at work significantly contribute to a subjective need for recovery.

Sonnentag (2003) has also recently highlighted the importance of recovery for subsequent work behaviour to the extent that recovery during leisure influences both the degree of work engagement and proactive behaviour at work; daily fluctuations in behaviour and attitudes at work were also found to be related to opportunities to recover in the nonwork domain.

Meijman and Mulder's (1998) Effort-Recovery model provides a useful framework for the psychological study of workload (see Figure 1). Work demands (e.g., working hours) without sufficient recovery, can lead to negative load effects (e.g., fatigue) and longer term losses of function, physical and mental impairment. The work procedure results in physiological and psychological reactions, which in principle are reversible. Under normal conditions, psychobiological systems stabilize at baseline levels when stressors are absent - this return to prestressor levels of functioning is known as recovery, during which homeostasis of physiological and psychological systems is achieved (Craig \& Cooper, 1992).

\section{CYCLES OF WORK AND REST}

It is intuitive that after work a period of recovery is required, perhaps achieved through simple rest or a change of activity. Fatigue and recovery 


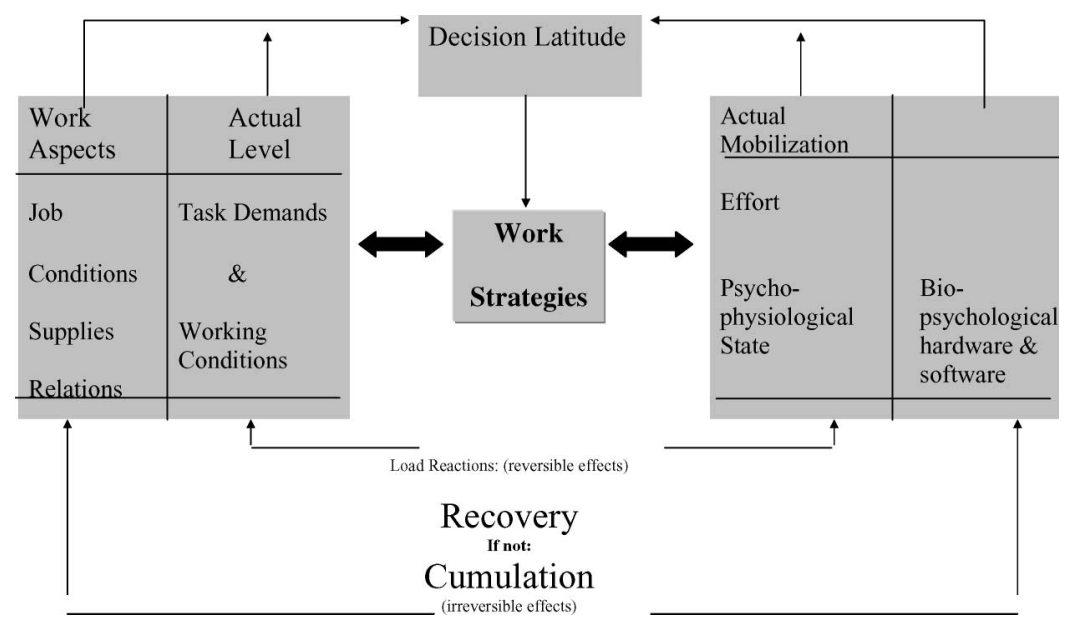

Figure 1. Effort-Recovery Model (Meijman \& Mulder, 1998).

are related concepts: Fatigue is the state that results from having been exposed to work demands, and recovery is the process of replenishing the depleted resources or rebalancing suboptimal systems. Occupationally induced fatigue is a central concept since failure to recover from its effects, evidenced in selfreport data (e.g., Sluiter et al., 1999), can lead to negative consequences for health and organizational well-being. Indeed, elevated fatigue scores are used to identify those at risk of absenteeism or work disability (Bültmann et al., 2000), and could theoretically be used to identify individuals who have failed to recover from the short-term effects of a workday. Lack of recovery results in fatigue, thus fatigue can be used as a proxy to recovery; the term "recovery" is used in the remainder of the article to indicate a level of functioning or wellbeing, as indicated by reduction in fatigue scores.

Nonwork time is essential for recovery since (traditionally at least) work demands are absent. Whilst short-term load reactions are in principle reversible, time is a crucial variable. Occupationally induced fatigue is theorized not to be a problem if adequate recovery time is offered between two periods of exposure to work demands (Sluiter et al., 2001). If the psychological systems used during work are activated during recovery time, or the recovery is insufficient, a cumulative process involving prolonged fatigue, sleep complaints, and psychosomatic complaints may ensue.

Insufficient recovery is predicted to lead to a vicious cycle whereby extra effort needs to be invested at every successive work period in order to rebalance suboptimal psychophysiological states and to maintain performance (Sluiter et al., 1999; Sluiter et al., 2001). In the event of this "nonoptimal" state, occupationally induced fatigue may eventually develop into Chronic Fatigue Syndrome (CFS). Inadequate work-rest ratios 
are perhaps a causal factor in the development of CFS (Ray, Weir, Cullen, \& Phillips, 1992). Sluiter et al. (2001) reported that higher levels of neuroendocrine reactivity after work (indicating poor recovery) predicted a higher number of reported health complaints. In a sense, lack of recovery is a type of sustained arousal. Burnout, which is associated with fatigue and inadequate coping (i.e., recovery), is another longer term health outcome that may be expected.

\section{RESPITES AND RECOVERY PROCESSES}

Research has demonstrated the beneficial and salutary effects of a temporary detachment and relief from job stressors on psychological and physiological variables (e.g., burnout, cortisol levels). Hobfoll and Shirom (2001) indicated that a relaxation period between stress episodes allows regrouping of resources. Westman and Eden's (1997) quasiexperimental studies revealed that burnout scores were lower during and after a 2-week vacation, although the relief was short-lived. Subsequent research has repeatedly demonstrated that stress levels fall during holiday periods (Eden, 2001). Etzion, Eden, and Lapidot (1998) extended the scope of this research to suggest that nonwork time of any sort helps to manage stress and relieve the symptoms of burnout; during and after vacation periods, sabbaticals, and leisure time generally, stress levels decrease and psychological symptoms such as burnout decrease, whilst well-being is enhanced. Physiological field studies have also evidenced decreased cortisol levels during leisure time, in addition to an increase in physiological reactions when work demands increase (e.g., Evans \& Steptoe, 2001; Frankenhaeuser, 1989).

Although workers in Europe can normally expect a vacation of some sort during an average year, it seems that individuals require additional chances for recovery, especially when considering that the salutary effects of vacations have been found to fade out quickly, with dependant variables such as burnout and well-being rapidly returning to their prevacation levels soon after returning to work (Westman \& Eden, 1997; Westman \& Etzion, 2001). Thus, the daily recovery that occurs in the evenings after normal working days or during the traditional weekend respite becomes important to maintaining well-being and performance (Sonnentag, 2003). Various developments in the organization of work are believed to affect the time available for recovery; changes in work arrangements, i.e., the use of ICT, dual career families, homeworking, telecommuting, flexitime, sharing, and negotiating family responsibilities all affect the time available for recovery (Frankenhaeuser, Lundberg, Fredrikson, Melin, Tuomisto, Myrsten, et al., 1989; Roe et al., 1994; Zijlstra, Schalk, \& Roe, 1996).

Based on these considerations and other indications that working hours and travel (daily commute to work) can increase stress and 
fatigue (Frankenhaeuser, 1989; Spurgeon \& Cooper, 2001) our first hypothesis is:

Hypothesis 1: The amount of time spent on work and travel time will be negatively related to recovery. As stated before, reduction of fatigue will be used as a proxy of the recovery process. This means that we expect a positive association between the amount of time spent on work and travel and fatigue scores.

Emerging research has elucidated aspects of daily recovery by examining the contribution of leisure activities to recovery (Sonnentag, 2001). Using theoretical models to make predictions, such as the beneficial effects of low-effort and cognitively undemanding tasks following the Effort-Recovery model, Sonnentag's study examined the effects on recovery using the diary method. This research has been pivotal in providing the conceptual, theoretical, and empirical basis for the study of daily recovery activities. Job-related activities, such as preparing for work the next day, were predicted to inhibit recovery since recovery can only occur when work demands are absent. Similarly, household activities (e.g., cleaning) were predicted to prevent recovery since they often have a high degree of obligation and will threaten resources if performed whilst fatigued. Low-effort activities (e.g., watching TV) enable recovery since they are passive and place few demands on mental resources. Social activities (e.g., visiting friends) facilitate recovery since stressors are absent, thus facilitating return of prestressor levels of functioning. Physical activities are beneficial for recovery since different resources are used to those typically used at work. Moreover, physical activity has been extolled as a beneficial activity in its own right, becoming an "antidote" to anxiety and stress (Hull, 1990; Iso-Ahola, 1997; Iwasaki, 2001). Results from a recent longitudinal analysis confirms a strong inverse association between physical activity and the onset of chronic fatigue; those who exercise less than once a week are significantly more likely to be fatigued at follow-up (Bültmann, Kant, Kasl, Schroer et al., 2002). Sonnentag found that the amount of time spent on low-effort, physical, and social activities is conducive to recovery on a daily basis as measured by situational well-being (an affective component of the stress response), whilst job-related activities during nonwork time had deleterious effects. On the basis of these findings and to the extent that fatigue indicates the level of recovery and situational functioning we hypothesized that:

Hypothesis 2: The amount of time spent on household activities will be negatively related to recovery, as indicated by higher fatigue scores. 
Hypothesis 3: The amount of time spent on low-effort, physical, and social activities will be positively to recovery, as indicated by a reduction in fatigue scores.

Studies of daily recovery have neglected to include measures of sleep, arguably a crucial recovery activity in its own right. Sleep is bound with fatigue and appears in scales designed to assess the impact of fatigue on daily functioning (Craig \& Cooper, 1992; Ray et al., 1992). To the extent that sleep serves restorative functions and maintains performance (Campbell, 1992; Horne, 2001; Jouvet, 1999; Tilley \& Brown, 1992), it is necessary to account for this phenomenon. Mikulincer, Babkoff, Caspy, and Sing (1989) report that sleep deprivation leads to fatigue, in turn reducing motivation. Research by Zijlstra and de Vries (2000) has indicated that sleep is important for recovery. Individuals with high levels of fatigue typically have fewer hours of sleep and require extra effort investment during the morning and afternoon in comparison to individuals with low levels of fatigue. Åkerstedt et al. (2002) report that aspects of job stress, failing to exercise, and doing household chores after work are all risk factors for disturbed sleep. In their model, high work demands lead to a difficulty unwinding and recovering after work; in turn this leads to sleep problems that consequently lead to higher demands the following day, i.e., needing to invest extra effort to maintain performance. It is reasonable to suppose that fatigue resulting from work stress and poor sleep quality will disincline individuals to engage in leisure activities. Moreover, levels of fatigue are suggested to be differentially effected by degree of sleep quality, rather than just quantity (e.g., Craig \& Cooper, 1992). It has also been reported that the subjective component of sleep, as measured by self-report ratings of sleep quality, are more important than sleep quantity (Pilcher, 2000). To the extent that sleep quality may be more important than simply sleep quantity, it is reasonable to predict:

Hypothesis 4: Higher sleep quality will be positively related to recovery, as indicated by the proxy of fatigue scores.

Normally, people spend less time at work or work-related activities during the weekend. Therefore we expect that there will be an opportunity for recovery during the weekend. So, levels of fatigue should drop significantly over the weekend, and sleep quality should increase. Therefore our fifth hypothesis is:

Hypothesis 5: Fatigue scores will be higher during the week than during the weekend.

The present study aimed to gain some insight into the recovery processes during a normal working week and the extent to which the various leisure 


\section{4}

(nonwork) activities engaged in contribute to fatigue and thus recovery. The level of demand and effort of prototypical activities will also be highlighted. The present study also aimed to shed empirical light upon the work - rest cycle during a normal week whilst remaining nonintrusive. Daily recovery activities are investigated using a diary technique during which frequent, prestructured entries are made into paper diaries. Daily diary studies are ideal for tracking psychological phenomena over time (Harris, Daniels, \& Briner, 2003) and capture data closer to the actual changes in fatigue levels, therefore making the data more reliable and less likely to suffer recall effects associated with retrospective measurements.

\section{METHOD}

\section{Design}

Diaries obtained data over 7 days, typical of a normal working week and weekend respite. Respondents logged the amount of time spent engaged in specific activities during nonwork time, whilst recording sleep patterns and completing a daily fatigue questionnaire. Diaries were similar to those previously used (cf. Sonnentag, 2000), but are unique in terms of measures, layout, and duration. Attention was given to the structure of diaries to ensure a user-friendly format, i.e., A5-sized flipchart format, with clear and precise examples of how to complete it. Respondents started filling out the diaries on the Sunday, running through to the following Sunday to obtain a full week's scores.

\section{Participants}

A sample of the working age population was recruited from three different organizations: $39 \%$ from a petroleum company, $46 \%$ from an IT company, and $15 \%$ from an opportunity sample. An Occupational Health fair provided a recruitment opportunity whereby appreciation of a "diary" could be supplemented by verbal instruction. Additional to verbal instruction during recruitment (to obtain informed consent and assurances of anonymity), clear and comprehensive instructions were given along with the diaries. Initially 109 individuals were approached for participation; a $42 \%$ response rate put the final sample at $N=46$. With 18 men (39\%) and 28 women (61\%), mean age of respondents was 34.93 years (range $=40, S D=11$ ). Occupational roles varied: $n=13$ respondents in technical and information technology roles, 10 managers, 10 administrators, 5 academics, 4 customer services and support workers, 2 directors, and 2 health professionals. The majority of respondents were single or living with a partner (59\% single; $41 \%$ married); $59 \%$ had no children, $6.5 \%$ had one child, $24 \%$ had two children, $9 \%$ had three children, and $2 \%$ had four children $(M=0.89)$. There were no significant differences 
between the average weekly hours worked by males and females in the current sample in comparison to national averages (Office for National Statistics, 1998): males, $t(17)=-0.88, p>.05$ (two-tailed); females, $t(27)=-1.87, p>$ .05 (two-tailed).

\section{Measures}

After-work activities. Respondents were provided with a table for each day containing a list of five prototypical activities; ${ }^{1}$ these include: workrelated tasks (e.g., responding to work e-mail), household tasks (e.g., cooking, cleaning, looking after children), low-effort tasks that are not demanding (e.g., listening to music), physical activities (e.g., playing sport), and social activities (e.g., visiting friends). Respondents logged the amount of time spent on each activity category per day (minutes and hours).

Fatigue. A measure of fatigue was used as a proxy of recovery, fatigue was assessed daily using the Checklist Individual Strength (CIS-20R; Vercoulen et al., 1994), ${ }^{2}$ a 20 -item self-report instrument measuring several aspects of fatigue rated on a 7 -point scale $(1=$ "Yes, that is true", $7=$ "No, that is not true"): the subjective feeling of fatigue ( 8 items, $\alpha=.86$ ), concentration ( 5 items, $\alpha=.92$ ), motivation ( 4 items, $\alpha=.76$ ), and physical activity ( 3 items, $\alpha=.80$ ). Subscales were scored to produce a composite ranging from 20 to 140 (total CIS $\alpha=.83$ ), higher scores indicating a greater level of fatigue, more concentration problems, reduced motivation, and less activity. Although epidemiological studies utilize predefined cut-off points to define fatigued cases, fatigue is best studied along a continuum (Bültmann, 2002); therefore higher scores are conceptualized as a lesser degree of recovery and vice versa. Respondents completed the CIS 30 minutes before retiring to allow for the ameliorating or inhibitive effects of intervening activity. The CIS questions individuals about fatigue during the past 2 weeks, but the instruction was changed by the authors for use in the present study to ask individuals to indicate how they felt during the current day. In this sense it was adapted to be a situational measure of fatigue. Items in the checklist remained the same. Internal consistency coefficients ${ }^{3}$ indicated reliability of the measure.

\footnotetext{
${ }^{1}$ These prototypical activities are based on those previously used with minor additions (cf. Sonnentag, 2001).

${ }^{2}$ Copy obtained for use in the present research from the authors: J. H. M. M Vercoulen and G. Bleijenberg, University Hospital, Nijmegen.

${ }^{3}$ Cronbach's alpha levels are for CIS scores on Wednesday, giving an indication of how consistently fatigue levels are reported. Note: Alpha levels are similar to those previously reported, e.g., $\alpha=.9$ in Beurskens et al. (2000).
} 
Sleep and sleep quality. Respondents kept a sleep diary (adapted from Morin, 1993) answering eight questions in the morning before leaving for work. This diary provided the following relevant parameters: total sleep time (TST), calculated from sleep onset latencies, and time in bed (TIB). A sleep efficiency index (SEI; \%) is calculated from a ratio of TST and TIB. Two items allow respondents to rate sleep quality (SQ) and feeling upon arising (FUA): "When I got up this morning I felt" $1=$ "Exhausted, 5= "Very refreshed", and "Overall, my sleep last night was" $1=$ "Very restless", $5=$ "Very sound" $(\alpha=.86)$. Previous empirical research validated the use of subjective measures of sleep and sleep quality (e.g., Killen, George, Marchini, Silverman, \& Thoresen, 1982), which often correlate well with objective measures (i.e., Johns \& Dore, 1978).

Work situation/demand variables. Respondents reported the amount of time spent (hours and minutes) on contractual work and travelling to and from work. Job characteristics were assessed using a 10-item questionnaire derived from Karasek's (1979) model (adapted by Cropley, Steptoe, \& Joekes, 1999): Three dimensions were assessed: perceived demand (3 items), job control (3 items), and skill utilization (4 items), rated on a 4-point scale where 1 = "Strongly disagree", 4 = "Strongly agree".

\section{Data analysis}

Data were analysed using SPSS 11.0. Continuous time data was calculated for each respondent at both the day level and averaged across the total working week; thus for the proxy of fatigue, individual scores existed for each day of the week in addition to a summed and averaged total for the entire working week. Data were examined both at the week (averaging scores over the 7 days) and day level using $t$-tests and repeated measures ANOVA; pairwise comparisons were used to examine the significant differences in the major study variable scores for each day of the week. Zero-order correlations and regression analysis also enabled trends to be elucidated in addition to the predictor effects of work variables, recovery activities themselves, and also sleep variables. Although a cases-to-IV ratio of $N \geq 50+8 \mathrm{~m}$ is suggested to run multiple regressions (Tabachnick \& Fidell, 2001), the current sample size $(N=46)$ is adequate following a minimum requirement of five times more cases than IVs (Coakes \& Steed, 2001). In addition to screening and replacement of missing values using mean substitution for a small amount of cases, no univariate outliers $(z>3.29)$ were identified. Distribution of continuous variables, such as time data and fatigue, was found to be normal with no significant skewness or kurtosis. 


\section{RESULTS}

\section{Relationship between after-work activities and recovery}

Table 1 shows the zero-order correlations between the major study variables. Partial support for Hypothesis 3 was found: Time spent on physical activity is strongly negatively related to fatigue. However, low-effort and social activities $(n s)$ were associated with increases in fatigue (i.e., recovery inhibitive). In support of Hypothesis 4, sleep is negatively related to fatigue, with sleep quality rather than quantity emerging as a significant variable.

To examine the specific contribution of leisure activities and the other main study variables to the experience of fatigue, a linear multiple regression was employed using fatigue as the dependent variable. However, first a regression analysis was run to ascertain whether demographic information significantly predicts elevated fatigue. In comparison to the constant-only model, the model with demographic information was not statistically significant $(F=0.83$, $p=.53$ ), indicating that age, sex, marital status, presence of children, and occupation, as a set, do not reliably distinguish between fatigued individuals. With regards to individual predictors, beta statistics confirmed that none of the demographics reliably predicted fatigued status.

In the linear regression analysis all predictors were entered into one model simultaneously to ascertain their specific contribution to the increase or decrease in fatigue scores. No multivariate outliers $(>26.12)$ were identified using Mahalanobis distance, $p<.001$ criterion. Table 2 summarizes the results of the analysis. The model contained work hours and travel, recovery activities, and sleep parameters. As a set, these predictors were significant, $F(9,36)=5.47, p<.01$, accounting for $47 \%$ of the variance in fatigue levels.

Individual coefficients showed that work and travel time did not significantly contribute to fatigue (i.e., Hypothesis 1 was not supported). Time spent on household activities was not related to fatigue, i.e., Hypothesis 2 was not supported). Time spent on physical activities is significantly associated with decreases in the experience of fatigue, $\beta=-.39$, $t=-2.88, p<.01$. Individually, physical activity accounts for $9.67 \%$ of the variance in fatigue $\left(s r^{2}-.276\right)$ (partly support for Hypothesis 3). Sleep quality and feeling upon arising emerged as significant predictors, associated with decreases in fatigue as subjective ratings increase, $\beta=-.38, t=-2.55$, $p<.05$, accounting for $7.62 \%\left(s r^{2}-.311\right)$ of the unique variance in fatigue scores (supporting Hypothesis 4). None of the other major study variables entered into the equation significantly predicted fatigue.

\section{Cycle of recovery during the week}

Figure 2 demonstrates the typical pattern of recovery over the course of a working week. Levels of fatigue are highest at the beginning of the week 


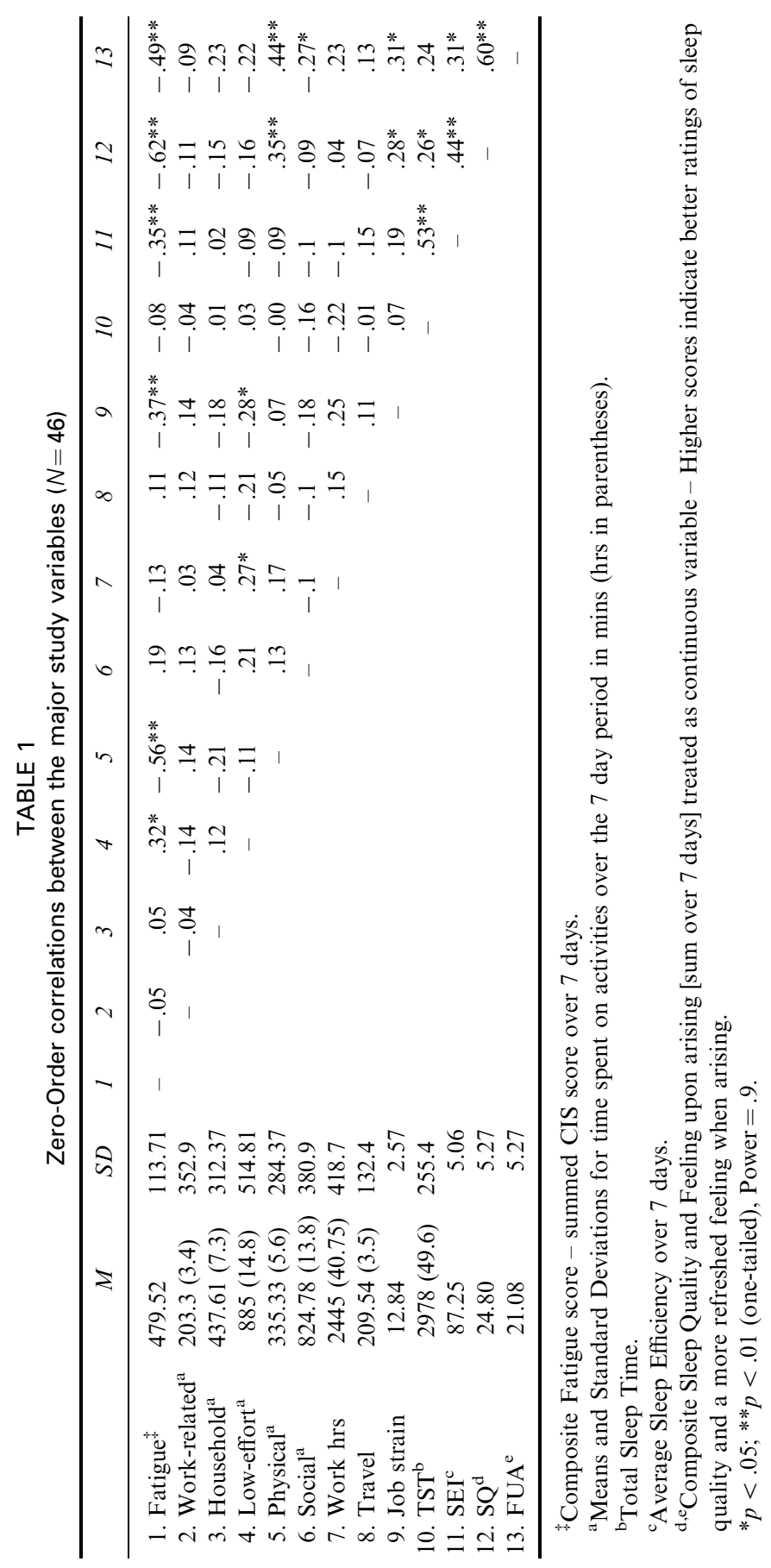


TABLE 2

Multiple Regression Analysis for variables predicting overall Fatigue scores $(N=46)$

\begin{tabular}{llccc}
\hline & Variable & $\beta$ & $t$ & Adjusted $R^{2}$ \\
\hline Model 1 & Total time-Work-Related & -.012 & -0.106 & \\
& Total time-Household & -.100 & -0.799 & \\
& Total time-Low-Effort & .157 & 1.351 & \\
Total time-Physical & $-.385^{* *}$ & -2.875 & \\
Total time-Social & .137 & 1.128 & \\
Sleep Quality + FUA & $-.380^{*}$ & -2.546 & \\
Average Overall Sleep Efficiency & -.191 & -1.367 & \\
Time for Sleep & .149 & 1.087 & $R^{2}=.58$ \\
Work + Travel Time & .017 & 0.130 & Adjusted $R^{2}=.47$ \\
& & & & $R=.76$ \\
\hline
\end{tabular}

$* p<.05 ; * * p<.01$

(Monday and Tuesday) with a sharp decline towards the end of the week and over the weekend - indeed both the linear and quadratic trend evidenced in Figure 2 is significant: linear $F(1,45)=12.81, p=.001, \mathrm{MS}_{\text {fatigue }}=4260$; quadratic $F(1,45)=9.33, p=.004, \mathrm{MS}_{\text {fatigue }}=1623$. To test the significance of these differences in fatigue over the week, pairwise comparisons revealed that there are significantly lower levels of fatigue on Sunday in comparison to all the other six days of the week (mean difference $=12.50, p<.01$ ). Fatigue levels on Wednesday are significantly higher in comparison to both days during the weekend (mean difference $=7.18$ and 13.47, respectively, $p<.05$ ). These results seem to be demonstrating the traditional function of a weekend "respite"; additional support is found from paired-samples $t$-tests: Fatigue during the week is significantly higher than fatigue over the weekend: Wed:Sat, $t(45)=2.02, p=.04$, one-tailed; Wed:Sun, $t(45)=4.22, p<.01$, one-tailed. This supports our fifth hypothesis. Correlations also suggest that higher fatigue during the weekend is associated with increased fatigue during the week: Wed-Sun, $r=.51, p \leq .01$, one-tailed; Mon-Sun, $r=.66, p \leq .01$, one-tailed. This suggests that lack of recovery during the weekend spills over into the working week (i.e., higher level of fatigue on Monday).

Interestingly, following previous research (e.g., Bültmann, 2002), 39\% of participants in the present study would be considered at risk of sickness absence due to fatigue. This is utilizing a cut-off point of CIS20R $>76$ whereby those individuals scoring above that score are at risk.

\section{Effects of sleep on recovery}

On average, respondents obtained just over 7 hours sleep per night with an average sleep efficiency of $87 \%$. Sleep time increases over the weekend, as 


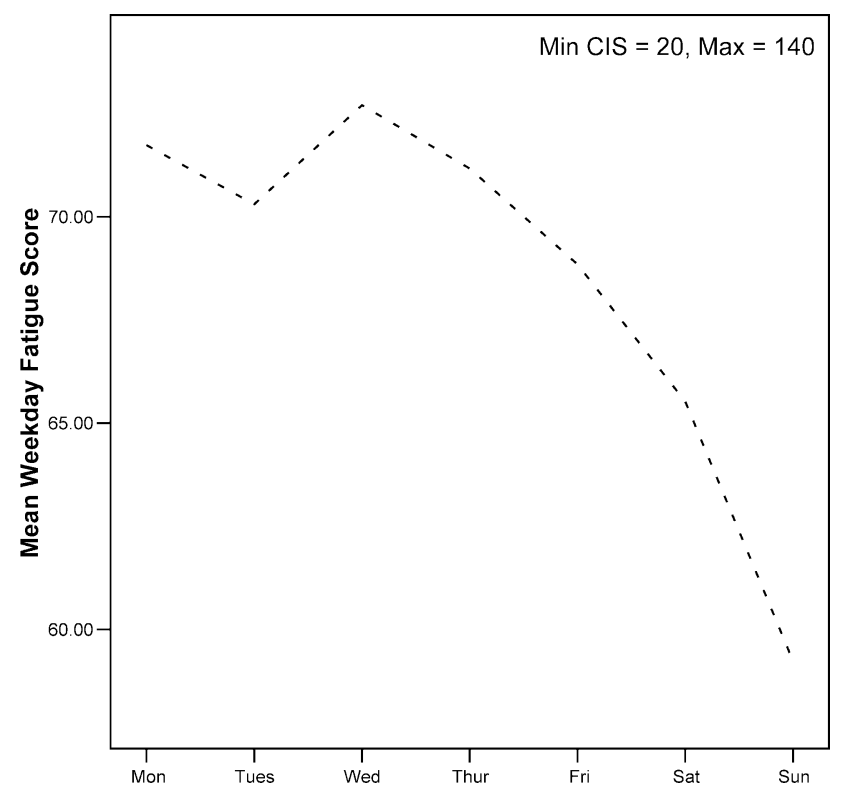

Figure 2. Pattern of recovery over the week.

does the level of sleep quality and feelings upon arising. Correlations in Table 1 suggest that sleep is beneficial to recovery. Figure 3 shows the changes to the levels of sleep quality over the course of the week; highest levels observed over the weekend, with the lowest ratings typically observed on Monday morning. Pairwise comparisons from the repeated measures ANOVA showed that sleep quality ratings were significantly lower on Mondays, Tuesdays, and Thursdays in comparison to the Saturday sleep quality ratings (mean difference $=-0.46,-0.45$, and -0.44 respectively, $p<.05)$. These results support the trend of a weekend respite in the sleep data. The pairwise comparisons also revealed a significant linear trend towards feeling more refreshed upon arising at the weekends: linear $F(1,45)=4.26, p=.045, \mathrm{MS}_{\text {fatigue }}=4.14$. Respondents reported significantly higher feelings upon arising (FUA) ratings on Saturday in comparison to all other working days (Mon - Fri mean difference $=0.58, p<.05$ ). As can be seen in Figure 3, the lowest sleep quality ratings appear on Monday. However, it should be noted that these ratings are obtained on Monday morning, and refer to the Sunday's sleep episode. This may seem counterintuitive, but could indicate the anticipation of work demands.

\section{Work variables}

No significant effects or differences were found for travel time (Mon-Fri). Respondents report an average job strain of $12.84(S D=2.57)$. With $17.4 \%$ 


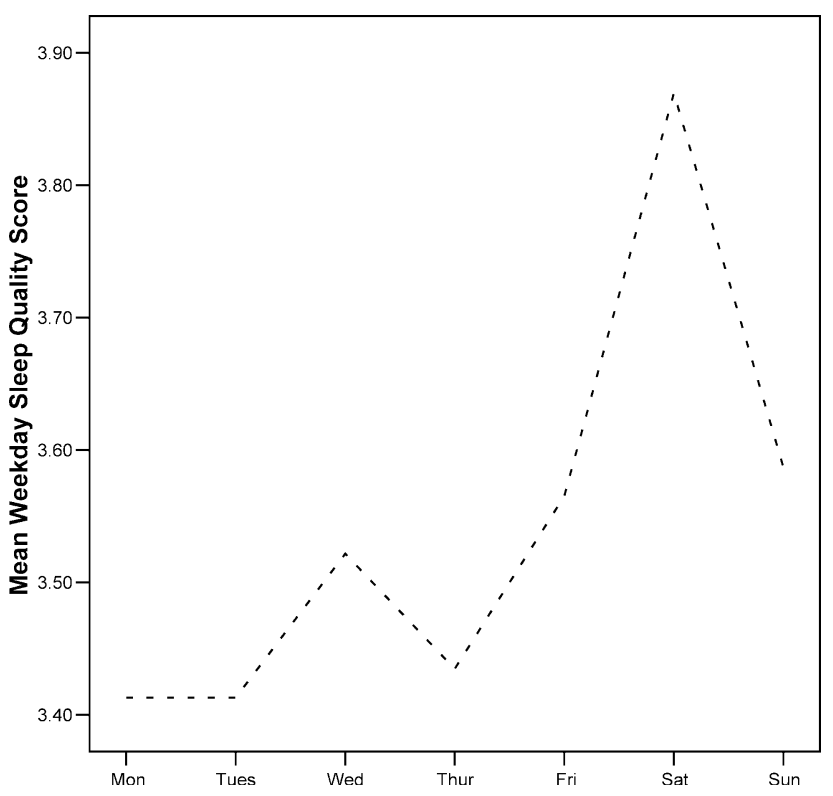

Figure 3. Pattern of sleep quality over the week.

$(n=8)$ of the sample scoring 10 or below (good balance between demand/ control and low strain), $82.6 \%(n=38)$ report higher strain in relation to their work. In comparison to previous studies; ${ }^{4}$ however, the sample report significantly lower job strain scores, $t(45)=-7.8, p<.01$, two-tailed; thus respondents are not in a statistical sense "high strain".

\section{DISCUSSION}

The 46 respondents in the current study provided a wide range of data on the nature of recovery activities in relation to fatigue, sleep, and work situation variables. The results indicated that the amount of time spent on work and travel, and also the amount of time spent on work-related activities after work time did not contribute to predicting fatigue. Such a finding is consistent with some other studies who failed to find a direct association between number of hours worked and fatigue, in particular when people have a choice in deciding to work long hours (i.e., the higher level or white collar jobs, as in this sample; see Josten, 2002). People who spend a lot of time on their job usually do like their work, and thus do not experience fatigue. Contrary to prediction and recent findings (e.g., Sonnentag, 2001), low-effort and social activities were not conducive to recovery after work. Low-effort activities were even associated

\footnotetext{
${ }^{4}$ One-sample $t$-test with the mean statistic of 15.8 utilized by Cropley et al. (1999) to define those in high strain occupations.
} 
with increases in fatigue. These activities are generally rather passive, and might not help to disengage from work activities. Their passive nature may even enhance feelings of fatigue and apathy and lethargy (Iso-Ahola, 1997). In this respect it should be brought to attention that our measure of fatigue was primarily a measure for the subjective experience of fatigue, rather than feelings of physical fatigue (after physical exercise), and therefore is believed to encompass a strong motivational component (Meijman, 1991; Zijlstra, 1993). Low-effort activities may therefore be beneficial for recovery from physical fatigue rather than from psychological fatigue. Moreover, since the diaries were unable to measure cognitive and psychological demands from work in a more detailed way (i.e., more than simple job strain questionnaire), it is impossible to conclude whether this result is due to low demands at work, thus causing loweffort activity during leisure to diminish recovery effects, or whether low-effort activities simply don't aid recovery. On the other hand it might be that people who feel fatigued may find themselves too tired to engage in any activities other than low-effort, thus suggesting that low-effort activities are not conducive to recovery. However, our study is consistent with findings that life-styles with low amounts of exercise results in more feelings of fatigue (e.g., Bültmann, Kant, Kasl, Schroer, Swaen, \& Van den Brandt, 2002b; Jette, 1997).

The finding that the second hypothesis was not supported can also be explained from this perspective: Household activities, in particular caring for children, require active involvement. For that reason these activities help to disengage from the daily strains of work. Therefore they may even be seen as beneficial for recovery.

With regard to recovery conducive activities, it was demonstrated that greater time spent engaged in physical activity increased recovery levels, thus providing partial support for the second hypothesis; moreover, individuals with low levels of fatigue spent significantly more time engaged in physical activities. Although it was beyond the scope of the present research to isolate the precise mechanisms involved, such as the positive effects of endorphins (Steinberg et al., 1998), social support (Jones \& Bright, 2001), and general well-being (Iwasaki, 2001), physical activity emerged as a strong individual factor benefiting recovery (with a large effect size). The EffortRecovery model is also supported if the recovery is accounted for in terms of engaging in an activity conceptually different from work tasks or indeed simply allowing homeostasis to restore following the passage of time and acquisition of resources to offset future loss.

In support of our fourth hypothesis, sleep appears to be crucial to daily recovery from strain, i.e., it is significantly negatively related to fatigue scores. It was discovered that the better participants felt immediately upon arising and the more positive the ratings of the sleep episode, the less likely one is to experience fatigue at the end of the workday. Extensive research has previously confirmed the importance of sleep with regards to maintaining 
optimal performance (Campbell, 1992), preserving memory (Tilley \& Brown, 1992), and cerebral functions (Horne, 2001; Jouvet, 1999); sleep in the present research, moreover its quality rather than amount of sleep, emerges as important to recovery. Analysis revealed that after accounting for work variables and intervening activities, sleep quality predicts recovery by reducing the experience of fatigue. It was also discovered that there were no significant differences in recovery when accounting for the duration of a sleep episode; this variable also failed to predict recovery. Thus similar to previous findings that sleep quality can predict subjective sleepiness and mood states (such as vigour) better than simple sleep quantification (e.g., Pilcher, 2000), the subjective component of sleep in the present findings emerge as more important than sleep quantity. Exactly why individuals report better sleep quality remains unclear since a physiologic examination was not possible; correlations might suggest that similar to other findings (e.g., Horne, 2001) sleep quantity plays a role in maintaining sleep quality, and therefore affecting recovery indirectly. One aspect not accounted for by the diaries was the beneficial effect of afternoon naps in maintaining alertness and reducing fatigue.

This study confirmed the importance of the traditional weekend respite since a substantial amount of recovery occurred over Saturday and Sunday: Individuals are significantly less fatigued, with parallel significant increases in sleep quality ratings and feelings upon arising. Indeed, the trend of a sharp decline in fatigue over the weekend was statistically significant. Saturday appeared to be a particularly beneficial day for recovery with regards improved sleep - it seems entirely possible that this "pinnacle day" for recovery carries over recovery effects into Sunday, explaining why fatigue levels are lowest on this day (i.e., highest levels of recovery). These beneficial effects are attributed to a period of "time off" when the pressures of work are absent, thus allowing return to prestressor levels of functioning; evidently this level of recovery is not possible during the working week. Lowest levels of recovery at the beginning of the week appear to contradict the respite effect since fatigue may be expected to be lower immediately after "time off": This can be explained in terms of "fade out". Westman and Eden (1997) found that subsequent to a vacation, burnout returned towards prevacation levels within three days; in the present case we suggest that the same mechanisms (i.e., effort-recovery) operate over the weekend, yet since this respite is only 2 days and a vacation typically much longer, this shorter duration accounts for a rapid return to highest stress (fatigue) levels. The weekend respite still operates but fades rapidly in the course of work schedules (Fritz \& Sonnentag, 2005; Strauss-Blasche, Muhry, Lehofer, Moser, \& Marktl, 2004). Significantly, higher fatigue scores during the weekend are related to higher fatigue on Monday; the suggestion is that if individuals are not fully recovered over the weekend, there might still be fatigue residuals on Monday. This will result in extra effort having to be exerted at the beginning of the successive week; the short-term load reactions of exerting this 
extra effort during Monday is evidenced by the higher fatigue scores on that evening. These results are indicative of the "vicious cycle" described by previous authors, e.g., Meijman and Mulder (1998) and Sluiter et al. (1999). Tentatively one could hypothesize that the long-term effects of insufficient recovery, such as chronic fatigue or burnout, might only manifest themselves after a long period of these cycles and poor short-term recovery; future research would seek to confirm these effects, but the trend has been elucidated.

It is interesting to note that sleep quality ratings on Monday were quite low. These ratings were obtained on Monday morning and reflect the Sunday's sleep episode. This could point in the direction of an anticipation of work demands. People start thinking of their work on Sunday evening, and start to worry, which subsequently affects their sleep quality. Indeed, our findings of anticipation of work demands and a "fade out" of respite effects is supported by recent medical research that has demonstrated a Monday morning surge in blood pressure that is associated with significant increases in deleterious cardiovascular events on Mondays, such as myocardial infarctions and strokes (Murakami et al., 2004). Thus, the recovery trends in our data are borne out by research that lends credence to the idea of a stressful change from weekend leisure activities to work activities on Monday that require mental and physical exertion. Individuals are reactivated on Mondays, both in a physiological and psychological sense.

Work variables of working time and travel time remained nonsignificant to aspects of recovery from fatigue. Although their trends are in line with the traditional working week and weekend respite, they exerted no significant effects on the outcome hypothesized variables in the study. Higher job strain was significantly negatively related to fatigue and time spent on low-effort activities: These findings seem strange in light of established links between job strain and stress reactions (e.g., Jones \& Bright, 2001) and recent research demonstrating that job strain increases fatigue (Bültmann et al., 2002a). This anomaly is explicable in terms of "eustress" (Selye, 1976) and adaptive levels of "high activity" (Schabraq, Cooper, Travers, \& van Maanen, 2001). Individuals may agree with statements pertaining to demands in their work (i.e., "the pace of work in my job is very intense") yet not suffer short-term reactions. One imagines healthy workers doing a "tough" day's work, with high levels of stress hormones circulating, yet during leisure time successfully return to prestressor levels. If this were the case, they wouldn't report high levels of fatigue and could conversely report increases in recovery if they feel satisfied with the day's work or experience "positive pressure". The finding that increased job strain is related to better sleep quality supports this theorizing. By enhancing self-esteem and producing satisfaction with achievement of goals (Furnham, 1997), a "hard" day at work (i.e., active jobs) need not result in negative reactions. Clearly, the long-term effects of job strain are unlikely to be detected by this "snapshot" into recovery processes 
(e.g., cardiovascular disease; Karasek \& Theorell, 1990). Since respondents were not "statistically" high strain, our interpretation might be that these workers don't require low-effort recovery, thus explaining the absence of effect.

Although males and females, old and young, married and single respondents pursue different leisure patterns, these characteristics do not differentiate them in terms of recovery. Whilst it would be interesting to create recovery profiles for certain groups, analyses revealed that a demographic model was not suitable for the prediction of recovery.

\section{Study limitations}

Several methodological issues need to be accounted for when interpreting our results. The sample size is relatively small in comparison to previous diary studies and therefore cannot be regarded as truly representative of the working population in the UK.

Control over when and where respondents completed sections of the diary remains problematic. It is impossible to conclude with any certainty whether respondents completed the sleep diaries shortly after arising, or whether the CIS was completed 30 minutes before retiring. Such issues present a challenge for future research: It is now possible to equip respondents with pagers or beepers to ensure regular responses and experimental intervals, or to consider the use of electronic diaries similar to those utilized in clinical trials. This would be a move towards the experience sampling method (ESM) that would allow tighter control and a good method of studying the experience of recovery activities and the concurrent measurement of recovery variables using electronic equipment. Reactance is another problem with the validity of results since keeping a diary could alter behaviour, thoughts, and feelings (Breakwell \& Wood, 2000); however, it has been suggested that leisure patterns are unlikely to be changed over such a short period (cf. Sonnentag, 2001). Nevertheless diary studies can be considered a useful method in this type of research.

Individual differences were not controlled for in this study. Dispositional factors such as Type A and B behaviour or negative affectivity are known to moderate reactions to stress (Jones \& Bright, 2001) and could therefore influence fatigue scores and recovery. For example, Type A individuals who are job focused and achievement orientated could exhibit higher job strain scores. The anomaly related to job strain in the present thesis could be due to an absence of Type A individuals.

\section{Practical implications}

Several applied aspects emerge from this research. Firstly, it is suggested that individuals and organizations pay more attention to the issue of recovery 
outside the workplace; organizations seem reluctant to become involved in nonwork life (O'Driscoll \& Cooper, 2002) but clearly nonwork time is necessary for individual recovery, without which individual and organizational "health" will suffer (Sonnentag, 2002). Occupational health should not just include work and organizational conditions, but also work - life balance and the challenges people face outside of the work domain. Interventions based on the present results will depend upon readers' personal evaluations, but several recommendations could be made. Firstly, physical activity seems to be a core aspect of recovery, particularly from the mentally demanding work faced by most individuals (Donkin, 2001). Individuals should maximize time spent on physical pursuits. Secondly, the weekend is a period that organizations should "preserve" in order to allow employees to recover; whilst this tradition is not overtly threatened, the increase in mobile technology and rapid communication devices means that individuals are more likely to engage the same psychological systems when not at work, or perhaps when "recovering" (e.g., Zijlstra et al., 1996). Direct intervention to improve sleep quality is also important —one possibility may be to ensure that work tasks or problems have received a degree of "closure" prior to leaving the work setting, thus ensuring that individuals do not "activate" themselves subsequently. Organizations might also consider paying particular attention to these issues on Monday, particularly when recovery over the medium-term, and possibly long-term, will depend upon psychological states on this day.

\section{Implications for future research}

Future research into daily recovery could make use of the present diaries, perhaps triangulating results with additional measures of recovery such as situational well-being. Longitudinal research could confirm the long-term structure of recovery activities and elucidate cumulative cycle effects. To supplement psychological variables, one could also include some physiological indices of recovery (e.g., blood pressure, heart rate, hormone secretions), mapping objective proxies of the recovery process against selfreports. A physiological examination of sleep (e.g., "activity watches" to monitor nocturnal movements) may help to elucidate aspects that enhance sleep quality. Baseline and control measures of fatigue taken shortly after returning to the home setting were not obtained due to concerns about order effects, an excess of data and the suitability of the CIS for such use. However, control scores of recovery at the end of the workday would allow more precise isolation of the effects of recovery activities when compared to scores taken before going to bed. An additional way to expand upon the present research is to use comparison groups of respondents from the same organization, with the same work roles: one group including employees with tendencies towards low-effort recovery and sedentary lifestyles, whilst the 
latter would include individuals who engage in physical and active leisure; rates of recovery could then be compared.

\section{CONCLUSION}

This study demonstrated that it is necessary to look at general lifestyle patterns (including leisure and sleep) if one wants to understand the effects of job stressors on peoples' health. Recovery from daily strain is determined by the work - rest cycle. What constitutes successful recovery may ultimately differ across individuals. Only through replications will psychologists arrive at a more precise understanding of what constitutes successful recovery on the fatigue continuum. Replications with a larger sample are strongly recommended, which could help elucidate cut-off points for recovery, i.e., scores that represent successful recovery. Perhaps what emerges is that stress and our adaptation to it (i.e., fatigue) is an individual process. Individuals need to discover their own thresholds and live at a pace of life suited to their needs: For Selye (1976, p. 413), "Activity and rest must be judiciously balanced, and every person has his own characteristic requirements for rest and activity." Some individuals may maintain health and avoid deleterious outcomes by taking regular short breaks or holidays (Cartwright \& Cooper, 1997); others may require episodes of recovery on a daily basis involving physical activity. If individuals recognize that a bout of physical activity prepares them for rest and sleep, or conversely that they become "activated" and fatigued by completing work tasks, they should adopt strategies or reach compromises with employers to enable them to achieve a personal balance.

\section{REFERENCES}

Åkerstedt, T., Knutsson, A., Westerholm, P., Theorell, T., Alfredsson, L., \& Kecklund, G. (2002). Sleep disturbances, work stress and work hours: A cross-sectional study. Journal of Psychosomatic Research, 53, 741-748.

Beurskens, A. J. H. M., Bültmann, U., Kant, I., Vercoulen, J. H. M. M., Bleijenberg, G., \& Swaen, G. M. H. (2000). Fatigue among working people: Validity of a questionnaire measure. Occupational and Environmental Medicine, 57, 353-357.

Breakwell, G. M., \& Wood, P. (2000). Diary techniques. In G. M. Breakwell, S. Hammond, \& C. Fife-Schaw (Eds.) Research methods in psychology (2nd ed., pp. 294-302). London: Sage.

Bültmann, U. (2002). Fatigue and psychological distress in the working population: The role of work and lifestyle. Maastricht, The Netherlands: Universitaire Pers Maastricht.

Bültmann, U., de Vries, M., Beurskens, A. J. H. M., Bleijenberg, G., Vercoulen, J. H. M. M., \& Kant, I. (2000). Measurement of prolonged fatigue in the working population: Determination of a cutoff point for the checklist individual strength. Journal of Occupational Health Psychology, 5(4), 411-416.

Bültmann, U., Kant, I., Kasl, S., Beurskens, A. J. H. M., \& van den Brandt, P. A. (2002a). Fatigue and psychological distress in the working population: Psychometrics, prevalence, and correlates. Journal of Psychosomatic Research, 52(6), 445-452. 
Bültmann, U., Kant, I., Kasl, S. V., Schroer, K. A. P., Swaen, G. M. H., \& van den Brandt, P. A. (2002b). Lifestyle factors as risk factors for fatigue and psychological distress in the working population: Prospective results from the Maastricht Cohort Study. Journal of Occupational and Environmental Medicine, 44, 116-124.

Campbell, S. S. (1992). Effects of sleep and circadian rhythms of performance. In A. P. Smith \& D. M. Jones (Eds.), Handbook of human performance: Vol. 3. State and trait (pp. 195-235). London: Academic Press.

Cartwright, S., \& Cooper, C. L. (1997). Managing workplace stress. London: Sage.

Coakes, S. J., \& Steed, L. G. (2001). SPSS analysis without anguish. Chichester, UK: Wiley.

Confederation of British Industry [CBI]. (2001). Healthcare brief: Business and healthcare for the 21st century. London: Author.

Craig, A., \& Cooper, R. E. (1992). Symptoms of acute and chronic fatigue. In A. P. Smith \& D. M. Jones (Eds.), Handbook of human performance: Vol. 3. State and trait (pp. 289-339). London: Academic Press.

Cropley, M., Steptoe, A., \& Joekes, K. (1999). Job strain and psychiatric morbidity. Psychological Medicine, 29, 1411-1416.

Department for Work and Pensions [DWP]. (2002). Pathways to work: helping people into employment [Green Paper]. London: Author.

Donkin, R. (2001). Blood, sweat and tears: The evolution of work. New York: Texere.

Eden, D. (2001). Vacations and other respites: Studying stress on and off the job. In C. L. Cooper \& I. T. Robertson (Eds.), Well-being in organisations: A reader for students and practitioners (pp. 121-146). Chichester, UK: Wiley.

Etzion, D., Eden, D., \& Lapidot, Y. (1998). Relief from job stressors and burnout: Reserve service as a respite. Journal of Applied Psychology, 83(4), 577-585.

Evans, O., \& Steptoe, A. (2001). Social support at work, heart rate, and cortisol: A selfmonitoring study. Journal of Occupational Health Psychology, 6(4), 361-370.

Frankenhaeuser, M. (1989). A biopsychosocial approach to work life issues. International Journal of Health Services, 19, 747-758.

Frankenhaeuser, M., Lundberg, U., Fredrikson, M., Melin, B., Tuomisto, M., Myrsten, A.-L., et al. (1989). Stress on and off the job as related to sex and occupational status in whitecollar workers. Journal of Organizational Behavior, 10, 321-346.

Fritz, C., \& Sonnentag, S. (2005). Recovery, health, and job performance: Effects of weekend experiences. Journal of Occupational Health Psychology, 10, 187-199.

Furnham, A. (1997). The psychology of behaviour at work: The individual in the organisation. Hove, UK: Psychology Press.

Harris, C., Daniels, K., \& Briner, R. B. (2003). A daily diary study of goals and affective wellbeing at work. Journal of Occupational and Organizational Psychology, 76(3), 401-410.

Hobfoll, S. E., \& Shirom, A. (2001). Conservation of resources theory: Applications to stress and management in the workplace. In R. T. Golembiewski (Ed.), Handbook of organizational behavior (2nd ed., pp. 57-80). New York: Marcel Dekker.

Horne, J. A. (2001). State of the art: Sleep. The Psychologist, 14(6), 302-306.

Hull, B. R. (1990). Mood as a product of leisure: Causes and consequences. Journal of Leisure Research, 22(2), 99-111.

Iso-Ahola, S. E. (1997). A psychological analysis of leisure and health. In J. T. Haworth (Ed.), Work, leisure and well-being (pp. 131-144). London: Routledge.

Iwasaki, Y. (2001). Contributions of leisure to coping with daily hassles in university students' lives. Canadian Journal of Behavioural Science, 33(2), $128-141$.

Jette, M. (1997). Stress coping through physical activity. In A. S. Sethi \& R. S. Schuler (Eds.), Handbook of organisational stress coping strategies (pp. 84-103). Cambridge, MA: Ballinger.

Johns, M. W., \& Dore, C. (1978). Sleep at home and in the sleep laboratory: Disturbance by recording procedures. Ergonomics, 21(5), 325-330. 
Jones, F., \& Bright, J. (Eds.). (2001). Stress: Myth, theory and research. Upper Saddle River, NJ: Prentice Hall.

Josten, E. (2002). The effects of extended workdays (PhD thesis, Tilburg University). Assen, The Netherlands: VanGorcum Publishers.

Jouvet, M. (1999). The paradox of sleep: The story of dreaming. London: MIT Press.

Karasek, R. A. (1979). Job demands, job decision latitude and mental strain: Implications for job redesign. Administrative Science Quarterly, 24, 285-308.

Karasek, R. T., \& Theorell, T. (1990). Healthy work, stress and productivity in working life. New York: Basic Books.

Killen, J. D., George, J., Marchini, E., Silverman, S., \& Thoresen, C. (1982). Estimating sleep parameters: A multitrait-multimethod analysis. Journal of Consulting and Clinical Psychology, 50(3), 345-352.

Kompier, M. A. J. (1988). Work and health of city bus drivers. Delft, The Netherlands: Eburon.

Landsbergis, P. A. (2003). The changing organization of work and the safety and health of working people: A commentary. Journal of Occupational and Environmental Medicine, 45(1), $61-72$.

Meijman, T. F. (1991). Over Vermoeidheid [Over fatigued; Psychological studies on perception of workload effects]. Unpublished PhD thesis, Groningen University, The Netherlands.

Meijman, T. F., \& Mulder, G. (1998). Psychological aspects of workload. In P. J. D. Drenth, H. Thierry, \& C. J. deWolff (Eds.), Handbook of work and organisational psychology: Vol. 2. Work psychology (2nd ed., pp. 5-33). Hove, UK: Psychology Press.

Mikulincer, M., Babkoff, H., Caspy, T., \& Sing, H. (1989). The effects of 72 hours of sleep loss on psychological variables. British Journal of Psychology, 80, 145-162.

Moncrieff, J., \& Pomerleau, J. (2000). Trends in sickness benefits in Great Britain and the contribution of mental disorders. Journal of Public Health Medicine, 22(1), 59-67.

Morin, C. M. (1993). Insomnia: Psychological assessment andmanagement. London: Guilford Press.

Murakami, S., Otsuka, K., Kubo, Y., Shinagawa, M., Yamanaka, T., Ohkawa, S., \& Kitaura, Y. (2004). Repeated ambulatory monitoring reveals a Monday morning surge in blood pressure in a community-dwelling population. American Journal of Hypertension, 17, 11791183.

O'Driscoll, M. P., \& Cooper, C. L. (2002). Job-related stress and burnout. In P. Warr (Ed.), Psychology at work (5th ed.). London: Penguin.

Office for National Statistics. (1998). Average hours usually worked per week by full-time employees: By gender, EU comparison, 1998, Social Trends, 30. Dataset: ST30418. Retrieved June 25, 2002, from http://www.statistics.gov.uk/statbase

Pawlikowska, T., Chalder, T., Hirsch, S. R., Wallace, P., Wright, D. J. M., \& Wessely, S. C. (1994). Population based study of fatigue and psychological distress. British Medical Journal, 308, $763-766$.

Pilcher, J. J. (2000). Self-report sleep habits as predictors of subjective sleepiness. Behavioural Medicine, Winter. Retrieved 6 December 2001, from http://www.findarticles.com

Ray, C., Weir, W. R. C., Cullen, S., \& Phillips, S. (1992). Illness perception and symptom components in chronic fatigue syndrome. Journal of Psychosomatic Research, 36(3), 243256.

Roe, R. A., van den Berg, P. T., Zijlstra, F. R. H., Schalk, M. J. D., Taillieu, T. C. B., \& van der Wielen, J. M. M. (1994). New concepts for a new age: Information service organizations and mental information work. The European Work and Organizational Psychologist, 3(2), 177- 192.

Rystedt, L. W., Johansson, G., \& Evans, G. W. (1998). A longitudinal study of workload, health and well-being among male and female urban bus drivers. Journal of Occupational and Organisational Psychology, 71, 35-45.

Schabracq, M., Cooper, C., Travers, C., \& van Maanen, D. (2001). Occupational health psychology: The challenge of workplace stress. Leicester, UK: BPS Books. 
Selye, H. (1976). The stress of life. New York: McGraw-Hill.

Sluiter, J. K. (1999). How about work demands, recovery and health? A neuro-endocrine field study during and after work (PhD thesis). Amsterdam, The Netherlands: Studie Centrum Arbeid en Gezondheid, Academisch Medisch Centrum.

Sluiter, J. K., Frings-Dresen, M. H. W., van der Beek, A. J., \& Meijman, T. F. (2001). The relation between work-induced neuroendocrine reactivity and recovery, subjective need for recovery, and health status. Journal of Psychosomatic Research, 50, 29-37.

Sluiter, J. K., van der Beek, A. J., \& Frings-Dresen, M. H. W. (1999). The influence of workload on the need for recovery and experienced health: A study on coach drivers. Ergonomics, $42(4), 573-583$.

Sonnentag, S. (2000). Assessing daily recovery activities: First experiences with a diary method (Tech. Rep.). Konstanz, Germany: University of Konstanz.

Sonnentag, S. (2001). Work, recovery activities, and individual well-being: A diary study. Journal of Occupational Health Psychology, 6(3), 196-210.

Sonnentag, S. (2003). Recovery, work engagement and proactive behaviour: A new look at the interface between nonwork and work. Journal of Applied Psychology, 88(3), 518-528.

Spurgeon, A., \& Cooper, C. L. (2000). Working time, mental health and performance. In C. L. Cooper \& I. T. Robertson (Eds.), International review of industrial and organisational psychology (Vol. 15). Chichester, UK: Wiley.

Steinberg, H., Nicholls, B. R., Sykes, E. A., LeBoutillier, N., Ramlakhan, N., Moss, T. P., \& Dewey, A. (1998). Weekly exercise consistently reinstates positive mood. The European Psychologist, 3(4), $271-280$.

Strauss-Blasche, G., Muhry, F., Lehofer, M., Moser, M., \& Marktl, W. (2004). Time course of well-being after a three-week resort-based respite from occupational and domestic demands: Carry-over, contrast and situation effects. Journal of Leisure Research, 36(3), 293-309.

Tabachnick, B. G., \& Fidell, L. S. (2001). Using multivariate statistics (4th ed.). Needham Heights, AL: Allyn \& Bacon.

Tilley, A. J., \& Brown, S. (1992). Sleep deprivation. In A. P. Smith \& D. M. Jones (Eds.), Handbook of human performance: Vol. 3. State and trait (pp. 237-288). London: Academic Press.

Vercoulen, J. H. M. M., Swanink, C. M. A., Fennis, J. F. M., Galma, J. M. D., van der Meer, J. W. M., \& Bleijenberg, G. (1994). Dimensional assessment of chronic fatigue syndrome. Journal of Psychosomatic Research, 38(5), 383-392.

Westman, M., \& Eden, D. (1997). Effects of a respite from work on burnout: Vacation relief and fade-out. Journal of Applied Psychology, 82(4), 516-527.

Westman, M., \& Etzion, D. (2001). The impact of vacation and job stress on burnout and absenteeism. Psychology and Health, 16, 595-606.

Zijlstra, F. R. H. (1993). Efficiency in work behaviour: A design approach for modern tools (PhD thesis, Delft University of Technology). Delft, The Netherlands: Delft University Press.

Zijlstra, F. R. H., \& de Vries, J. (2000). Burnout en de bijdrage van socio-demografische en werkgebonden variabelen [Burnout and the contribution of socio-demographic and workrelated variables]. In I. L. D. Houtman, W. B. Schaufeli, \& T. Taris (Eds.), Psychische Vermoeidheid en Werk: Cijfers, trends en analyses (pp. 83-95). Alphen a/d. Rijn, \the Netherlands: Samsom.

Zijlstra, F. R. H., Schalk, M. J. D., \& Roe, R. A. (1996). Veranderingen in de Arbeid. Consequenties voor Werkenden [Changes in work: Consequences for working people]. Tijdschrift voor Arbeidsvraagstukken, 12(3), 251-263. 